\title{
Federal budget slammed by health critics
}

$\mathrm{T}$ he Canadian government says it made "significant investments for health care" in the 2013 federal budget, but Opposition health critics vehemently disagree, criticizing the government for what they call modest investments in the health sector.

Liberal Health Critic Dr. Hedy Fry says the Conservative federal government seems to be making an effort to "gut funding in the health care sector."

"They are pulling the wool over the eyes of the Canadian public," says Fry. "There's almost nothing in the budget related to health ... you really have to dig to find anything."

The assertion from federal Minister of Health, Leona Aglukkaq, that "transfers to provinces and territories are at record highs and continue to grow," is misleading, says Fry. In fact, she says, these initiatives were put forth by thenPrime Minister Paul Martin's Liberal government in the 2004 federalprovincial health care agreement, "A 10Year Plan to Strengthen Health Care," which provided for transfer payments for health to increase by $6 \%$ each year.

When the budget was released March 21, Aglukkaq also mentioned new investments in palliative care, patient-oriented research, First Nations and Inuit health and other areas. "To do all this, while still staying on track to balance the federal books by 2015 , shows that our government continues to play a leadership role in health care," says Aglukkaq.

However, New Democratic Party Health Critic Libby Davies questions this leadership, pointing out that over the years "the Conservative government has regularly refused to meet with provincial and territorial Health Ministers, and unilaterally cut over $\$ 30$ billion from provincial health transfers. ... [It] has all but walked away from renewing the Health Accords which come up for renegotiation in 2014."

Davies says this year's investments in health care "absolutely fall short of what

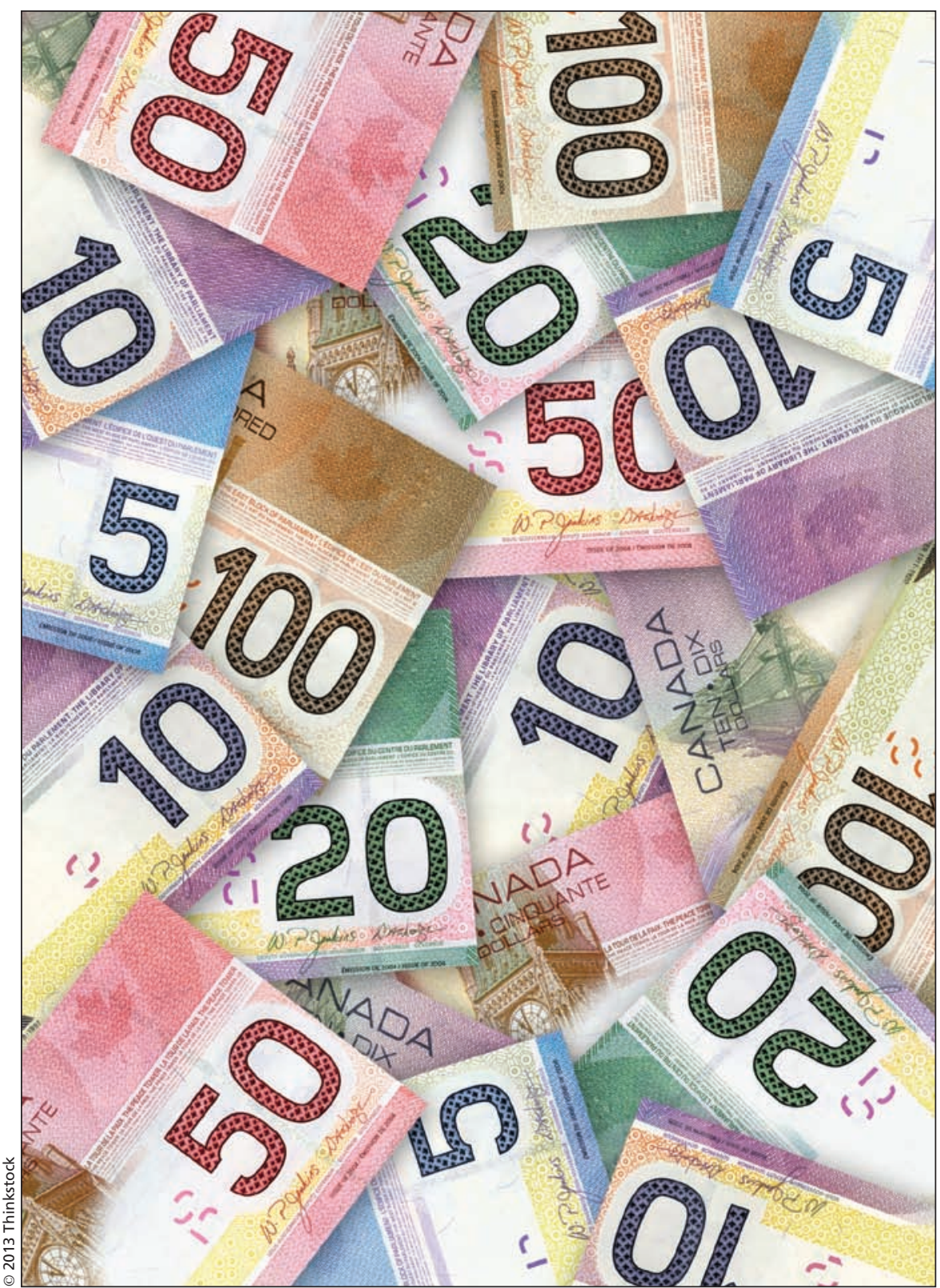

The Conservative government has "unilaterally cut over $\$ 30$ billion from provincial health transfers," says NDP Health Critic Libby Davies.

is needed to expand and strengthen our public health care system."

"The Conservative government is trying to pass responsibility for health care, and the costs associated with it, to the provinces and territories," Davies adds. "That is why there is so little funding for health care in this budget; the Conservative government is balanc- ing their budget on the backs of the provinces and territories."

As for the specifics of this year's budget, Fry laments the lack of new funding for mental health, and said that the Conservative government's increases in the mandatory minimum sentencing for those not found criminally responsible, clearly shows 
where the government's priorities lie with mental health.

Fry and Davies agree that the $\$ 3$ million allotted for palliative care training for primary care professionals and the sales tax exemption on provincially subsidized homecare services for seniors or the disabled, as well as on related medical supplies, is nowhere near the amount needed.

Davies called the investment in home care "woefully inadequate."

\section{Research response}

Meanwhile, the U15, a group of Canadian research-intensive universities, applauded the budget for contributing an additional $\$ 37$ million to the three granting councils: the Natural Sciences and Engineering Research Coun- cil, the Canadian Institutes of Health Research, and the Social Sciences and Humanities Research Council.

The U15's statement commended the government for an additional $\$ 165$ million in funding for Genome Canada, continued support for the Canada Foundation for Innovation and the \$141 million in new money to the National Research Council.

"In a time of financial constraint, this government has prudently chosen to maintain funding to the crucial innovation sectors that will help generate solutions to our pressing social and economic challenges," stated U15 President Amit Chakma, who is also the president of Western University, London, Ontario.
However, Fry points out that these investments in the research and development sector focus on applied research instead of basic research. Funding to the latter could foster growth and innovation as opposed to catering to commercial interests, she added.

Davies is more broadly critical: "The Conservatives are set on waging a war on knowledge by abolishing critical health research tools such as the long-form census, while at the same time firing hundreds of federal government researchers, muzzling scientists, and massively reducing funding for science and technology research." Adam Miller, CMAJ

CMAJ 2013. DOI:10.1503/cmaj.109-4452 